\title{
Front Matter: Volume 8669
}

, "Front Matter: Volume 8669," Proc. SPIE 8669, Medical Imaging 2013: Image Processing, 866901 (18 April 2013); doi: 10.1117/12.2021914

SDIE Event: SPIE Medical Imaging, 2013, Lake Buena Vista (Orlando Area), SPIE. Florida, United States 


\title{
PROGRESS IN BIOMEDICAL OPTICS AND IMAGING
}

Vol. 14 No. 36

\section{Medical Imaging 2013 \\ Image Processing}

\author{
Sebastien Ourselin \\ David R. Haynor \\ Editors
}

10-12 February 2013

Lake Buena Vista, Florida, United States

Sponsored by

SPIE

Cosponsored by

Aeroflex Incorporated - CREOL - The College Of Optics and Photonics, University of Central Florida (United States) • DQE Instruments, Inc. (Canada) • Medtronic, Inc. • PIXELTEQ,

Multispectral Sensing \& Imaging

Cooperating Organizations

AAPM-American Association of Physicists in Medicine (United States) - APS—American

Physiological Society • CARS—Computer Assisted Radiology and Surgery (Germany)

Medical Image Perception Society (United States) - Radiological Society of North America

(United States) • The DICOM Standards Committee (United States) • Society for Imaging

Informatics in Medicine (United States) • Florida Photonics Cluster (United States)

World Molecular Imaging Society

Published by

SPIE

Volume 8669

Part One of Two Parts

Proceedings of SPIE, 1605-7422, V. 8669

SPIE is an international society advancing an interdisciplinary approach to the science and application of light.

Medical Imaging 2013: Image Processing, edited by Sebastien Ourselin, David R. Haynor,

Proc. of SPIE Vol. 8669, 866901 - C 2013 SPIE · CCC code: 1605-7422/13/\$18

doi: $10.1117 / 12.2021914$

Proc. of SPIE Vol. $8669866901-1$ 
The papers included in this volume were part of the technical conference cited on the cover and title page. Papers were selected and subject to review by the editors and conference program committee. Some conference presentations may not be available for publication. The papers published in these proceedings reflect the work and thoughts of the authors and are published herein as submitted. The publisher is not responsible for the validity of the information or for any outcomes resulting from reliance thereon.

Please use the following format to cite material from this book:

Author(s), "Title of Paper," in Medical Imaging 2013: Image Processing, edited by Sebastien Ourselin, David R. Haynor, Proceedings of SPIE Vol. 8669 (SPIE, Bellingham, WA, 2013) Article CID Number.

ISSN: 1605-7422

ISBN: 9780819494436

Published by

SPIE

P.O. Box 10, Bellingham, Washington 98227-0010 USA

Telephone +1 3606763290 (Pacific Time) · Fax +1 3606471445

SPIE.org

Copyright (C) 2013, Society of Photo-Optical Instrumentation Engineers.

Copying of material in this book for internal or personal use, or for the internal or personal use of specific clients, beyond the fair use provisions granted by the U.S. Copyright Law is authorized by SPIE subject to payment of copying fees. The Transactional Reporting Service base fee for this volume is $\$ 18.00$ per article (or portion thereof), which should be paid directly to the Copyright Clearance Center (CCC), 222 Rosewood Drive, Danvers, MA 01923. Payment may also be made electronically through CCC Online at copyright.com. Other copying for republication, resale, advertising or promotion, or any form of systematic or multiple reproduction of any material in this book is prohibited except with permission in writing from the publisher. The CCC fee code is $1605-7422 / 13 / \$ 18.00$.

Printed in the United States of America.

Publication of record for individual papers is online in the SPIE Digital Library.

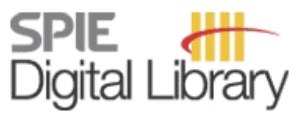

SPIEDigitalLibrary.org

Paper Numbering: Proceedings of SPIE follow an e-First publication model, with papers published first online and then in print and on CD-ROM. Papers are published as they are submitted and meet publication criteria. A unique, consistent, permanent citation identifier (CID) number is assigned to each article at the time of the first publication. Utilization of CIDs allows articles to be fully citable as soon as they are published online, and connects the same identifier to all online, print, and electronic versions of the publication. SPIE uses a six-digit CID article numbering system in which:

- The first four digits correspond to the SPIE volume number.

- The last two digits indicate publication order within the volume using a Base 36 numbering

system employing both numerals and letters. These two-number sets start with 00, 01, 02, 03, 04, $05,06,07,08,09,0 A, 0 B \ldots$. OZ, followed by 10-1Z, 20-2Z, etc.

The CID Number appears on each page of the manuscript. The complete citation is used on the first page, and an abbreviated version on subsequent pages. Numbers in the index correspond to the last two digits of the six-digit CID Number. 


\title{
Contents
}

\section{PART ONE}

\author{
xxi Conference Committee
}

SESSION 1 SEGMENTATION

866902 Efficient convex optimization-based curvature dependent contour evolution approach for medical image segmentation [8669-1]

E. Ukwatta, Robarts Research Institute (Canada) and The Univ. of Western Ontario (Canada); J. Yuan, W. Qiu, The Univ. of Western Ontario (Canada); M. Rajchl, A. Fenster, Robarts Research Institute (Canada) and The Univ. of Western Ontario (Canada)

866903 An automated algorithm for cell-level FISH dot counting [8669-2] Y. Al-Kofahi, D. Padfield, A. Seppo, GE Global Research (United States)

866904 Automatic cell segmentation in fluorescence images of confluent cell monolayers using multi-object geometric deformable model [8669-3]

Z. Yang, J. A. Bogovic, A. Carass, M. Ye, P. C. Searson, J. L. Prince, Johns Hopkins Univ. (United States)

866905 Local appearance features for robust MRI brain structure segmentation across scanning protocols [8669-4]

H. C. Achterberg, D. H. J. Poot, F. van der Lijn, M. W. Vernooij, M. A. Ikram, Erasmus MC (Netherlands); W. J. Niessen, Erasmus MC (Netherlands) and Delft Univ. of Technology (Netherlands); M. de Bruijne, Erasmus MC (Netherlands) and Univ. of Copenhagen (Denmark)

866906 Region-based graph cut using hierarchical structure with application to ground-glass opacity pulmonary nodules segmentation [8669-150]

C.-H. Tsou, K.-L. Lor, National Taiwan Univ. (Taiwan); Y.-C. Chang, National Taiwan Univ. Hospital (Taiwan); C.-M. Chen, National Taiwan Univ. (Taiwan)

\section{SESSION 2 DII/FUNCTIONAL}

866907 Fiber feature map based landmark initialization for highly deformable DTI registration [8669-6]

A. Gupta, Univ. of Pittsburgh (United States) and Univ. of North Carolina at Chapel Hill (United States); M. Toews, Harvard Medical School (United States); R. Janardhana, Univ. of North Carolina at Chapel Hill (United States); Y. Rathi, Harvard Medical School (United States); J. Gilmore, Univ. of North Carolina at Chapel Hill (United States); M. Escolar, Univ. of Pittsburgh (United States); M. Styner, Univ. of North Carolina at Chapel Hill (United States) 
866908 Morphological changes in the corpus callosum: a study using joint Riemannian feature spaces [8669-7]

M. Mani, IRISA/INRIA Rennes (France); A. Srivastava, Florida State Univ. (United States);

C. Barillot, IRISA/INRIA Rennes (France)

866909 Parcellation of the thalamus using diffusion tensor images and a multi-object geometric deformable model [8669-8]

C. Ye, J. A. Bogovic, Johns Hopkins Univ. (United States); S. H. Ying, Johns Hopkins Univ. School of Medicine (United States); J. L. Prince, Johns Hopkins Univ. (United States)

8669 OA Effects of DII spatial normalization on white matter tract reconstructions [8669-9] N. Adluru, Univ. of Wisconsin - Madison (United States); H. Zhang, Univ. College London (United Kingdom); D. P. M. Tromp, A. L. Alexander, Univ. of Wisconsin - Madison (United States)

8669 OB Susceptibility artefact correction by combining B0 field maps and non-rigid registration using graph cuts (Best Student Paper Award) [8669-10]

P. Daga, M. Modat, G. Winston, M. White, L. Mancini, A. W. McEvoy, J. Thornton, T. Yousry, J. S. Duncan, S. Ourselin, Univ. College London (United Kingdom)

8669 OC Functional brain atlas construction for brain network analysis [8669-11]

H. Li, Y. Fan, Institute of Automation (China)

8669 OD Multi-object statistical analysis of late adolescent depression [8669-12]

M. Ramezani, A. Rasoulian, P. Abolmaesumi, The Univ. of British Columbia (Canada);

T. Hollenstein, I. Johnsrude, K. Harkness, Queen's Univ. (Canada)

8669 OE Statistical shape representation with landmark clustering by solving the assignment problem [8669-13]

B. Ibragimov, B. Likar, F. Pernuš, T. Vrtovec, Univ. of Ljubljana (Slovenia)

8669 OF Quantitative vertebral morphometry in 3D [8669-14]

D. Štern, Univ. of Ljubljana (Slovenia); V. Njagulj, Clinical Ctr. of Vojvodina (Serbia); B. Likar, F. Pernuš, T. Vrtovec, Univ. of Ljubljana (Slovenia)

8669 OG Combining active appearance and deformable superquadric models for LV segmentation in cardiac MRI [8669-15]

S. Gopal, Cedars-Sinai Medical Ctr. (United States) and Univ. of California, Los Angeles (United States); Y. Otaki, R. Arsanjani, D. Berman, Cedars-Sinai Medical Ctr. (United States); D. Terzopoulos, Univ. of California, Los Angeles (United States); P. Slomka, Cedars-Sinai Medical Ctr. (United States) and David Geffen School of Medicine, Univ. of California, Los Angeles (United States)

$8669 \mathrm{OH} \quad$ Parsing radiographs by integrating landmark set detection and multi-object active appearance models [8669-16]

A. Montillo, Q. Song, X. Liu, J. V. Miller, GE Global Research (United States) 
8669 Ol Multiple sclerosis lesions evolution in patients with clinically isolated syndrome [8669-17] A. Crimi, O. Commowick, INRIA Rennes (France); J. C. Ferre, Ctr. Hospitalier Univ. de Rennes (France); A. Maarouf, Univ. Hospital Reims (France) and CRMBM, CNRS, AixMarseille Univ. (France); G. Edan, Ctr. Hospitalier Univ. de Rennes (France); C. Barillot, INRIA Rennes (France)

8669 0J Landmark detection and coupled patch registration for cardiac motion tracking [8669-18] H. Wang, W. Shi, Imperial College London (United Kingdom); X. Zhuang, Shanghai Advanced Research Institute (China); X. WU, K.-P. Tung, Imperial College London (United Kingdom); S. Ourselin, Univ. College London (United Kingdom); P. Edwards, D. Rueckert, Imperial College London (United Kingdom)

8669 OK Voxel-wise displacement as independent features in classification of multiple sclerosis [8669-19] M. Chen, Johns Hopkins Univ. (United States) and National Institute of Neurological Disorders and Stroke (United States); A. Carass, Johns Hopkins Univ. (United States); D. S. Reich, National Institute of Neurological Disorders and Stroke (United States); P. A. Calabresi, Johns Hopkins Univ. School of Medicine (United States); D. Pham, Ctr. for Neuroscience and Regenerative Medicine (United States); J. L. Prince, Johns Hopkins Univ. (United States)

8669 OL PCT derived arterial input function for improved pharmacokinetic analysis of longitudinal dceMRI for colorectal cancer [8669-20]

M. Enescu, M. Bhushan, Univ. of Oxford (United Kingdom); E. J. Hill, J. Franklin,

E. M. Anderson, R. A. Sharma, Oxford Univ. Hospitals NHS Trust (United Kingdom);

J. A. Schnabel, Univ. of Oxford (United Kingdom)

8669 OM Registration of multiple temporally related point sets using a novel variant of the coherent point drift algorithm: application to coronary tree matching [8669-21]

S. Habert, Siemens Corporate Technology (United States) and Ecole Polytechnique de Montréal (Canada); P. Khurd, C. Chefd'hotel, Siemens Corporate Technology (United States)

8669 ON Contextual filtering in curvelet domain for fluoroscopic sequences [8669-22]

C. Amiot, Thales Electron Devices (France) and GIPSA-Lab (France); J. Pescatore, Thales Electron Devices (France); J. Chanussot, M. Desvignes, GIPSA-Lab (France)

866900 Multimodal segmentation of optic disc and cup from stereo fundus and SD-OCT images [8669-23]

M. S. Miri, K. Lee, M. Niemeijer, The Univ. of lowa (United States); M. D. Abràmoff, The Univ. of lowa (United States) and U.S. Dept. of Veterans Affairs (United States); Y. H. Kwon, The Univ. of lowa (United States); M. K. Garvin, U.S. Dept. of Veterans Affairs (United States) and The Univ. of lowa (United States) 
8669 OP Ultrasound image segmentation using feature asymmetry and shape guided live wire [8669-24]

T. M. Rackham, S. Rueda, C. L. Knight, J. A. Noble, Univ. of Oxford (United Kingdom)

$86690 Q$ Automatic segmentation of right ventricle on ultrasound images using sparse matrix transform and level set [8669-25]

X. Qin, Z. Cong, L. V. Halig, Emory Univ. (United States); B. Fei, Emory Univ. (United States) and Georgia Institute of Technology (United States)

8669 OR Segmentation of retinal OCT images using a random forest classifier [8669-26]

A. Lang, A. Carass, Johns Hopkins Univ. (United States); E. Sotirchos, P. Calabresi, Johns Hopkins Univ. School of Medicine (United States); J. L. Prince, Johns Hopkins Univ. (United States)

8669 OS Classification of atorvastatin effect based on shape and texture features in ultrasound images [8669-27]

X. Yang, R. Wang, L. Li, Huazhong Univ. of Science and Technology (China); A. Fenster, The Univ. of Western Ontario (Canada); M. Ding, Huazhong Univ. of Science and Technology (China)

\section{SESSION 6 LUNG}

8669 OT Real time motion analysis in 4D medical imaging using conditional density propagation [8669-28]

J. Lotz, B. Fischer, J. Olesch, Fraunhofer MEVIS Project Group Image Registration (Germany); M. Günther, Fraunhofer MEVIS (Germany)

8669 OU Population based modeling of respiratory lung motion and prediction from partial information [8669-29]

D. Boye, Paul Scherrer Institut (Switzerland) and ETH Zurich (Switzerland); G. Samei, ETH Zurich (Switzerland); J. Schmidt, Univ. of Zurich (Switzerland) and ETH Zurich (Switzerland); G. Székely, C. Tanner, ETH Zurich (Switzerland)

8669 OV A derivative of stick filter for pulmonary fissure detection in CT images [8669-30]

C. Xiao, Hunan Univ. (China); M. Staring, Leiden Univ. Medical Ctr. (Netherlands); J. Wang, Hunan Univ. (China); D. P. Shamonin, B. C. Stoel, Leiden Univ. Medical Ctr. (Netherlands)

8669 OW Globally optimal lung tumor co-segmentation of 4D CT and PET images [8669-31] J. Bai, Q. Song, S. K. Bhatia, X. Wu, The Univ. of lowa (United States)

8669 0X Pulmonary lobe segmentation using the thin plate spline (TPS) with the help of the fissure localization areas [8669-32]

B. Odry, P. Steininger, L. Zhang, A. Kiraly, Siemens Corporate Technology (United States); A. Mahnke, Siemens AG (Germany); S. Sudarsky, C. Novak, B. Geiger, S. Qing, Siemens Corporate Technology (United States); H. Ditt, Siemens AG (Germany)

8669 OY Highly accurate fast lung CT registration [8669-33]

J. Rühaak, S. Heldmann, T. Kipshagen, B. Fischer, Fraunhofer MEVIS Project Group Image Registration (Germany) 
$8669 \mathrm{OZ}$ Assessing accuracy of non-linear registration in 4D image data using automatically detected landmark correspondences [8669-34]

R. Werner, Univ. Medical Ctr. Hamburg-Eppendorf (Germany); C. Duscha,

A. Schmidt-Richberg, J. Ehrhardt, H. Handels, Univ. of Lübeck (Germany)

866910 Deformable image registration by multi-objective optimization using a dual-dynamic transformation model to account for large anatomical differences [8669-35]

T. Alderliesten, J.-J. Sonke, Netherlands Cancer Institute - Antoni van Leeuwenhoek Hospital (Netherlands); P. A. N. Bosman, Ctr. voor Wiskunde en Informatica (Netherlands)

866911 Multimodal rigid-body registration of 3D brain images using bilateral symmetry [8669-36]

S. Prima, O. Commowick, INRIA, INSERM (France) and Univ. of Rennes, CNRS (France)

866912 CT colonography: inverse-consistent symmetric registration of prone and supine inner colon surfaces [8669-37]

H. R. Roth, J. R. McClelland, M. Modat, T. E. Hampshire, D. J. Boone, E. Helbren, A. Plumb,

M. Hu, S. Ourselin, S. Halligan, D. J. Hawkes, Univ. College London (United Kingdom)

866913 Statistical 3D prostate imaging atlas construction via anatomically constrained registration [8669-38]

M. Rusu, Case Western Reserve Univ. (United States); B. N. Bloch, C. C. Jaffe, Boston Univ. School of Medicine (United States); N. M. Rofsky, The Univ. of Texas Southwestern Medical Ctr. (United States); E. M. Genega, Beth Israel Deaconess Medical Ctr. (United States); E. Feleppa, Riverside Research Institute (United States); R. E. Lenkinski, The Univ. of Texas Southwestern Medical Ctr. (United States); A. Madabhushi, Case Western Reserve Univ. (United States)

866914 Mouse lung volume reconstruction from efficient groupwise registration of individual histological slices with natural gradient [8669-39]

H. Wang, M. Rusu, Case Western Reserve Univ. (United States); T. Golden, A. Gow, Rutgers, The State Univ. of New Jersey (United States); A. Madabhushi, Case Western Reserve Univ. (United States)

866915 Surrogate-based diffeomorphic motion estimation for radiation therapy: comparison of multivariate regression approaches [8669-40]

M. Wilms, Univ. of Lübeck (Germany); R. Werner, Univ. Medical Ctr. Hamburg-Eppendorf (Germany); J. Ehrhardt, A. Schmidt-Richberg, M. Blendowski, H. Handels, Univ. of Lübeck (Germany)

\section{SESSION 8 SEGMENTATION AND LOCALIZATION}

866916 Probabilistic model-based detection and localization of calibration phantoms in CT Images [8669-41]

M. Zheng, Virginia Tech-Wake Forest Univ. School of Biomedical Engineering and Sciences (United States) and Wake Forest Univ. School of Medicine (United States); J. J. Carr, Wake Forest Univ. School of Medicine (United States); Y. Ge, Virginia Tech-Wake Forest Univ. School of Biomedical Engineering and Sciences (United States) and Wake Forest Univ. School of Medicine (United States) 
866917 Coarse-to-fine localization of anatomical landmarks in CT images based on multi-scale local appearance and rotation-invariant spatial landmark distribution model [8669-42] M. Nemoto, The Univ. of Tokyo Hospital (Japan); Y. Masutani, The Univ. of Tokyo Hospital (Japan) and The Univ. of Tokyo (Japan); S. Hanaoka, Y. Nomura, The Univ. of Tokyo Hospital (Japan); S. Miki, The Univ. of Tokyo (Japan); T. Yoshikawa, N. Hayashi, The Univ. of Tokyo Hospital (Japan); K. Ohtomo, The Univ. of Tokyo Hospital (Japan) and The Univ. of Tokyo (Japan)

866918 Automated anatomical labeling of the cerebral arteries using belief propagation [8669-43] M. Bilgel, Johns Hopkins Univ. School of Medicine (United States); S. Roy, A. Carass, Johns Hopkins Univ. (United States); P. A. Nyquist, Johns Hopkins Univ. School of Medicine (United States); J. L. Prince, Johns Hopkins Univ. School of Medicine (United States) and Johns Hopkins Univ. (United States)

866919 A pattern recognition framework for vessel segmentation in 4D CT of the brain [8669-44] J. J. Mordang, M. T. H. Oei, R. van den Boom, Radboud Univ. Nijmegen Medical Ctr. (Netherlands); E. J. Smit, Univ. Medical Ctr. Utrecht (Netherlands); M. Prokop, B. van Ginneken, R. Manniesing, Radboud Univ. Nijmegen Medical Ctr. (Netherlands)

8669 1A Hepatic vein segmentation using wavefront propagation and multiscale vessel enhancement [8669-45]

K. Drechsler, C. Oyarzun Laura, S. Wesarg, Fraunhofer-IGD (Germany)

8669 1C A flexible toolkit for rapid GPU-based generation of DRRs for 2D-3D registration [8669-47] G. Marchelli, D. Haynor, W. Ledoux, Univ. of Washington (United States); R. Tsai, Univ. of Washington (United States) and Univ. College London (United Kingdom); D. Storti, Univ. of Washington (United States)

8669 ID Breast compression simulation using ICP-based B-spline deformation for correspondence analysis in mammography and MRI datasets [8669-48]

J. Krüger, J. Ehrhardt, Univ. of Lübeck (Germany); A. Bischof, Univ. Medical Ctr. SchleswigHolstein (Germany); H. Handels, Univ. of Lübeck (Germany)

8669 IE Semi-automatic registration of 3D orthodontics models from photographs [8669-49] R. Destrez, Lab. PRISME, Polytech'Orléans (France) and XTREMVIZ (France); S. Trevillet, Y. Lucas, Lab. PRISME, Polytech'Orléans (France); B. Albouy-Kissi, Univ. d'Auvergne (France)

$8669 \mathrm{IF} \quad$ Bias correction of maximum likelihood estimation in quantitative MRI [8669-50]

D. H. J. Poot, G. Kotek, Erasmus MC (Netherlands); W. J. Niessen, Erasmus MC (Netherlands) and Delft Univ. of Technology (Netherlands); S. Klein, Erasmus MC (Netherlands) 
8669 1G Near-lossless compression of computed tomography images using predictive coding with distortion optimization [8669-51]

A. Weinlich, Friedrich-Alexander-Univ. Erlangen-Nürnberg (Germany) and Siemens Corporate Technology (Germany); P. Amon, A. Hutter, Siemens Corporate Technology (Germany); A. Kaup, Friedrich-Alexander-Univ. Erlangen-Nürnberg (Germany)

$86691 \mathrm{H} \quad$ Tumor segmentation in brain MRI by sparse optimization [8669-52]

S. Wu, Univ. of Pennsylvania (United States); D. J. Rippe, Florida Hospital Zephyrhills (United States); N. G. Avgeropoulos, M.D. Anderson Cancer Ctr. (United States)

866911 Three-dimensional synthetic blood vessel generation using stochastic L-systems [8669-53] M. A. Galarreta-Valverde, M. M. G. Macedo, Univ. of São Paulo (Brazil); C. Mekkaoui, Harvard Medical School and Massachusetts General Hospital (United States); M. P. Jackowski, Univ. of São Paulo (Brazil)

$86691 \mathrm{~J} \quad$ Longitudinal intensity normalization of magnetic resonance images using patches [8669-54]

S. Roy, A. Carass, J. L. Prince, Johns Hopkins Univ. (United States)

$86691 \mathrm{~K} \quad$ Automatic neonatal brain tissue segmentation with MRI [8669-55] V. Srhoj-Egekher, Univ. of Zagreb (Croatia); M. J. N. L. Benders, Wilhelmina Children's Hospital, Univ. Medical Ctr. Utrecht (Netherlands); M. A. Viergever, I. Išgum, Univ. Medical Ctr. Utrecht (Netherlands)

$86691 \mathrm{~L} \quad$ Robust non-local multi-atlas segmentation of the optic nerve [8669-56] A. J. Asman, M. P. Delisi, L. A. Mawn, R. L. Galloway, B. A. Landman, Vanderbilt Univ. (United States)

$86691 \mathrm{M}$ Improving whole-brain segmentations through incorporating regional image intensity statistics [8669-57]

C. Ledig, Imperial College London (United Kingdom); R. A. Heckemann, A. Hammers, The Neurodis Foundation (France) and Imperial College London (United Kingdom);

D. Rueckert, Imperial College London (United Kingdom)

8669 iN Patch-based label fusion using local confidence-measures and weak segmentations [8669-58]

A. Mastmeyer, D. Fortmeier, E. Maghsoudi, Univ. of Lübeck (Germany); M. Simon, Univ. Medical Ctr. Schleswig-Holstein (Germany); H. Handels, Univ. of Lübeck (Germany)

\section{POSTER SESSION: ATLASES}

866910 Combined pixel classification and atlas-based segmentation of the ventricular system in brain CT Images [8669-59]

P. C. Vos, I. Išgum, J. M. Biesbroek, B. K. Velthuis, M. A. Viergever, Univ. Medical Ctr. Utrecht (Netherlands) 
8669 IP Constructing a 4D murine cardiac micro-CT atlas for automated segmentation and phenotyping applications [8669-60]

D. Clark, A. Badea, G. A. Johnson, C. T. Badea, Duke Univ. Medical Ctr. (United States)

$86691 \mathrm{Q}$ Build 4-dimensional myocardial model for dynamic CT images [8669-61]

Y. Liu, S. Liu, A. C. Lardo, K. Schuleri, M. S. Nacif, D. A. Bluemke, R. M. Summers, J. Yao,

National Institutes of Health (United States)

POSTER SESSION: BLOOD VESSELS

8669 IR A new morphological tool to extract blood vessels in cross sectional MRI [8669-62]

C. Blanchard, T. Sliwa, A. Lalande, O. Bouchot, Y. Voisin, Lab. Le2i, CNRS, Univ. de Bourgogne (France)

8669 is Automatic vessel extraction of lower extremity CT angiography using multi-segmented volume and regional vessel tracking [8669-63]

M. J. Lee, H. Hong, Seoul Women's Univ. (Korea, Republic of); J. W. Chung, Seoul National

Univ. Hospital (Korea, Republic of)

8669 IT Automatic detection of retinal vascular bifurcations and crossovers based on isotropy and anisotropy [8669-64]

G. Li, D. Xiang, F. Yang, X. Wan, X. Yang, J. Tian, Institute of Automation (China)

8669 IV A hardware implementation of a levelset algorithm for carotid lumen segmentation in CTA [8669-66]

A. van der Avoird, N. Lin, BIC Design (Netherlands); B. van Ginneken, R. Manniesing,

Radboud Univ. Nijmegen Medical Ctr. (Netherlands)

$86691 \mathrm{~W}$ Automated artery and vein detection in 4D-CT data with an unsupervised classification algorithm of the time intensity curves [8669-67]

H. O. A. Laue, Fraunhofer MEVIS (Germany); M. T. H. Oei, Radboud Univ. Nijmegen Medical Ctr. (Netherlands); L. Chen, I. N. Kompan, H. K. Hahn, Fraunhofer MEVIS (Germany);

M. Prokop, R. Manniesing, Radboud Univ. Nijmegen Medical Ctr. (Netherlands)

8669 1X 3D multiscale vessel enhancement based centerline extraction of blood vessels [8669-68] R. P. Kumar, Oslo Univ. Hospital (Norway) and Univ. of Oslo (Norway); F. Albregtsen, M. Reimers, Univ. of Oslo (Norway); T. Langø, SINTEF (Norway); B. Edwin, Oslo Univ. Hospital (Norway); O. J. Elle, Oslo Univ. Hospital (Norway) and Univ. of Oslo (Norway)

\section{POSTER SESSION: CLASSIFICATION}

8669 IY A method for automated anatomical labeling of abdominal veins extracted from 3D CT images [8669-69]

T. Matsuzaki, M. Oda, Nagoya Univ. (Japan); T. Kitasaka, Aichi Institute of Technology

(Japan); Y. Hayashi, Nagoya Univ. (Japan); K. Misawa, Aichi Cancer Ctr. Hospital (Japan);

K. Mori, Nagoya Univ. (Japan) 
$86691 \mathrm{Z}$ Graph-based bifurcation detection in phase-contrast MR images [8669-70]

Y.-J. Jeong, Karlsruhe Institute of Technology (Germany); S. Ley, Univ. Hospital Heidelberg (Germany) and Univ. of Toronto (Canada); M. Delles, R. Dillmann, R. Unterhinninghofen,

Karlsruhe Institute of Technology (Germany)

866920 Optimal filter approach for the detection of vessel bifurcations in color fundus images [8669-71]

Q. Hu, The Univ. of lowa (United States); M. K. Garvin, The Univ. of lowa (United States) and Iowa City VA Medical Ctr. (United States); M. A. Christopher, X. XU, T. E. Scheetz, The Univ. of lowa (United States); M. D. Abramoff, The Univ. of lowa (United States), lowa City VA Medical Ctr. (United States), and The Univ. of lowa Hospitals and Clinics (United States)

866921 Data-specific feature point descriptor matching using dictionary learning and graphical models [8669-72]

R. Guerrero, D. Rueckert, Imperial College London (United Kingdom)

866922 Automated temperature calculation method for DWI-thermometry: volunteer study [8669-73]

K. Sakai, Kyoto Univ. (Japan); K. Yamada, Kyoto Prefectural Univ. of Medicine (Japan);

N. Sugimoto, Kyoto Univ. (Japan)

866923 Colour and multispectral imaging for wound healing evaluation in the context of a comparative preclinical study [8669-74]

D. Nouri, Y. Lucas, S. Treuillet, Lab. PRISME, Univ. d'Orléans (France); R. Jolivot, F. Marzani, LE2i UFR Sciences et Techniques, Univ. de Bourgogne (France)

866924 Wound image analysis system for diabetics [8669-75]

L. Wang, P. C. Pedersen, D. Strong, B. Tulu, E. Agu, Worcester Polytechnic Institute (United States)

866925 Clustering of lung adenocarcinomas classes using automated texture analysis on CT images [8669-76]

A. Pires, H. Rusinek, J. Suh, D. P. Naidich, H. Pass, J. P. Ko, New York Univ. School of Medicine (United States)

\section{PART 2}

866926 Morphometric connectivity analysis to distinguish normal, mild cognitive impaired, and Alzheimer subjects based on brain MRI [8669-77]

L. Lillemark, L. Sørensen, P. Mysling, A. Pai, Univ. of Copenhagen (Denmark); E. B. Dam, Biomediq AS (Denmark); M. Nielsen, Univ. of Copenhagen (Denmark) and Biomediq (Denmark)

866927 Deformation texture-based features for classification in Alzheimer's disease [8669-78] N. T. Doan, B. van Lew, B. Lelieveldt, M. A. van Buchem, J. H. C. Reiber, J. Milles, Leiden Univ. Medical Ctr. (Netherlands) 
866928 3D spatio-temporal analysis for compressive sensing in magnetic resonance imaging of the murine cardiac cycle [8669-79]

B. Hirst, Y. R. Zheng, Missouri Univ. of Science \& Technology (United States); M. Yang, L. Ma, Univ. of Missouri (United States) and Harry S. Truman Memorial Veteran's Hospital (United States)

866929 Curvelets as a sparse basis for compressed sensing magnetic resonance imaging [8669-80]

D. S. Smith, L. R. Arlinghaus, T. E. Yankeelov, E. B. Welch, Vanderbilt Univ. (United States)

\section{POSTER SESSION: DIFFUSION TENSOR IMAGING}

8669 2A Software-based diffusion MR human brain phantom for evaluating fiber-tracking algorithms [8669-82]

Y. Shi, G. Roger, C. Vachet, F. Budin, E. Maltbie, A. Verde, M. Hoogstoel, J.-B. Berger, M. Styner, Univ. of North Carolina at Chapel Hill (United States)

$86692 \mathrm{~B}$ Connectivity-based parcellation of the postcentral gyrus using a spectral approach [8669-84]

T. Moreau, B. Gibaud, MediCIS team, INSERM (France)

8669 2C DTI quality control assessment via error estimation from Monte Carlo simulations [8669-85] M. Farzinfar, Y. Li, A. R. Verde, I. Oguz, Univ. of North Carolina at Chapel Hill (United States); G. Gerig, The Univ. of Utah (United States); M. A. Styner, Univ. of North Carolina at Chapel Hill (United States)

8669 2D UNC-Utah NA-MIC DII framework: atlas based fiber tract analysis with application to a study of nicotine smoking addiction [8669-86]

A. R. Verde, J.-B. Berger, Univ. of North Carolina at Chapel Hill (United States); A. Gupta, Univ. of North Carolina at Chapel Hill (United States) and Children's Hospital of Pittsburgh, Univ. of Pittsburgh (United States); M. Farzinfar, A. Kaiser, V. W. Chanon, C. Boettiger, Univ. of North Carolina at Chapel Hill (United States); H. Johnson, J. Matsui, The Univ. of lowa (United States); A. Sharma, The Univ. of Utah (United States); C. Goodlett, Kitware, Inc. (United States); Y. Shi, H. Zhu, Univ. of North Carolina at Chapel Hill (United States); G. Gerig, S. Gouttard, The Univ. of Utah (United States); C. Vachet, Univ. of North Carolina at Chapel Hill (United States) and The Univ. of Utah (United States); M. Styner, Univ. of North Carolina at Chapel Hill (United States)

$86692 \mathrm{E}$ Mapping longitudinal cerebral cortex development using diffusion tensor imaging [8669-87]

Y. Wang, Northwestern Polytechnical Univ. (China) and Univ. of North Carolina at Chapel Hill (United States); G. Li, M. Ahn, J. Nie, H. Zhu, Univ. of North Carolina at Chapel Hill (United States); L. Guo, Northwestern Polytechnical Univ. (China) 
POSTER SESSION: OPTICAL COHERENCE TOMOGRAPHY

$86692 \mathrm{~F}$ 3D image noise reduction and contrast enhancement in optical coherence tomography [8669-88]

K. Xu, Q. Wang, Samsung Advanced Institute of Technology (China); W. Jang, Samsung Advanced Institute of Technology (Korea, Republic of); Z. Hao, H. Ren, J. Kim, Samsung Advanced Institute of Technology (China)

\section{POSTER SESSION: IMAGE ENHANCEMENT}

$86692 \mathrm{G}$ Image denoising of low-radiation dose coronary CT angiography by an adaptive blockmatching 3D algorithm [8669-89]

D. Kang, Univ. of Southern California (United States); P. Slomka, R. Nakazato, Cedars-Sinai Medical Ctr. (United States); J. Woo, Univ. of Maryland (United States); D. S. Berman, Cedars-Sinai Medical Ctr. (United States); C.-C. J. Kuo, Univ. of Southern California (United States); D. Dey, Cedars-Sinai Medical Ctr. (United States)

$86692 \mathrm{H} \quad$ Pulse sequence based multi-acquisition MR intensity normalization [8669-90] A. Jog, S. Roy, A. Carass, J. L. Prince, Johns Hopkins Univ. (United States)

8669 2J Noise reduction using nonadditive Q-Gaussian filters in magnetic resonance images [8669-92]

I. J. A. Soares, L. O. Murta Jr., Univ. de São Paulo (Brazil)

8669 2K Multiscale TV flow with applications to fast denoising and registration [8669-93] P. Athavale, R. XU, Univ. of Toronto (Canada); P. Radau, Sunnybrook Research Institute (Canada); A. Nachman, Univ. of Toronto (Canada); G. Wright, Sunnybrook Research Institute (Canada)

8669 2L Robust blind deconvolution for fluorescence microscopy using GEM algorithm [8669-94] B. Kim, T. Naemura, The Univ. of Tokyo (Japan)

$86692 \mathrm{M}$ Image processing of infrared thermal images for the detection of necrotizing enterocolitis [8669-95]

R. Nur, Carleton Univ. (Canada); M. Frize, Carleton Univ. (Canada) and Univ. of Ottawa (Canada)

$86692 \mathrm{~N}$ Sparse dictionary representation and propagation for MRI volume super-resolution [8669-96]

X.-H. Han, Y.-W. Chen, Ritsumeikan Univ. (Japan)

POSTER SESSION: LABEL FUSION

866920 iSTAPLE: improved label fusion for segmentation by combining STAPLE with image intensity [8669-97]

X. Liu, A. Montillo, E. T. Tan, J. F. Schenck, GE Global Research (United States) 
$86692 \mathrm{P} \quad$ Tracking multiple neurons on worm images [8669-98]

T. Parag, Howard Hughes Medical Institute (United States); V. Butler, Univ. of Cambridge (United States); D. Chklovskii, Howard Hughes Medical Institute (United States)

$86692 \mathrm{Q}$ Involuntary motion tracking for medical dynamic infrared thermography using a templatebased algorithm [8669-99]

T.-Y. Cheng, C. Herman, Johns Hopkins Univ. (United States)

POSTER SESSION: REGISTRATION

$86692 R$ Volume-preserving correction of non-rigid registrations for the investigation of pleural thickening growth [8669-101]

P. Faltin, RWTH Aachen Univ. (Germany); T. Kraus, Univ. Hospital Aachen (Germany);

K. Chaisaowong, RWTH Aachen Univ. (Germany) and King Mongkut's Univ. of Technology North Bangkok (Thailand)

866925 A framework for automatic tuning of system parameters and its use in image registration [8669-102]

R. H. Gong, Z. Yaniv, Children's National Medical Ctr. (United States)

$86692 \mathrm{~T} 3 \mathrm{D}$ registration of histology and ultrasound data for validation of prostate cancer imaging [8669-103]

S. G. Schalk, T. A. Saidov, Eindhoven Univ. of Technology (Netherlands); H. Wijkstra, Eindhoven Univ. of Technology (Netherlands) and Academic Medical Ctr. Univ. Hospital (Netherlands); M. Mischi, Eindhoven Univ. of Technology (Netherlands)

$86692 \mathrm{U}$ Automatic measurement of wrist synovitis from contrast-enhanced MRI: a registrationcentered approach [8669-104]

P. Mysling, S. Darkner, J. Sporring, Univ. of Copenhagen (Denmark); E. Dam, M. Lillholm, Biomediq AS (Denmark)

$86692 \mathrm{~V} 2 \mathrm{D}$ registration guided models for semi-automatic MRI prostate segmentation [8669-105] R. Cheng, National Institutes of Health (United States); B. Turkbey, National Cancer Institute (United States); J. Senseney, National Institutes of Health (United States); M. Bernardo, National Cancer Institute (United States) and Frederick National Lab. (United States); A. Bokinsky, Geometric Tools, Inc. (United States); W. Gandler, E. McCreedy, T. Pohida, National Institutes of Health (United States); P. Choyke, National Cancer Institute (United States); M. J. McAuliffe, National Institutes of Health (United States)

$86692 \mathrm{~W}$ Monoplane stereoscopic imaging method for inverse geometry $\mathbf{x}$-ray fluoroscopy [8669-106]

M. T. Tomkowiak, M. S. Van Lysel, M. A. Speidel, Univ. of Wisconsin - Madison (United States) 
$86692 X$ Cortical correspondence via sulcal curve-constrained spherical registration with application to Macaque studies [8669-107]

I. Lyu, S. H. Kim, Univ. of North Carolina at Chapel Hill (United States); J.-K. Seong, Soongsil Univ. (Korea, Republic of); S. W. Yoo, Korea Advanced Institute of Science and Technology (Korea, Republic of); A. C. Evans, Montreal Neurological Institute, McGill Univ. (Canada); Y. Shi, Univ. of North Carolina at Chapel Hill (United States); M. Sanchez, Emory Univ. (United States); M. Niethammer, M. A. Styner, Univ. of North Carolina at Chapel Hill (United States)

8669 2Y Novel PET/CT image fusion via Gram-Schmidt spectral sharpening [8669-108]

R. T. Kneusel, Exelis Visual Information Solutions (United States); P. N. Kneusel, Colorado School of Mines (United States)

$86692 Z$ Characterisation of respiratory motion extracted from 4D MRI [8669-110]

A. A. Abd. Rahni, Univ. Kebangsaan Malaysia (Malaysia) and Univ. of Surrey (United Kingdom); E. Lewis, K. Wells, Univ. of Surrey (United Kingdom)

866930 Extracting respiratory motion from 4D MRI using organ-wise registration [8669-111] A. A. Abd. Rahni, Univ. Kebangsaan Malaysia (United Kingdom) and Univ. of Surrey (United Kingdom); R. Smith, E. Lewis, K. Wells, Univ. of Surrey (United Kingdom)

866931 Evaluation of 3D-2D registration methods for registration of 3D-DSA and 2D-DSA cerebral images [8669-1 12]

U. Mitrović, ž. Špiclin, Univ. of Ljubljana (Slovenia); B. Likar, F. Pernuš, Univ. of Ljubljana (Slovenia) and Sensum Computer Vision Systems (Slovenia)

866932 Super-resolution in cardiac MRI using a Bayesian approach [8669-113] N. Velasco Toledo, Univ. Militar Nueva Granada (Colombia) and Univ. Nacional de Colombia (Colombia); A. Rueda, C. Santa Marta, Univ. Nacional de Educación a Distancia (Spain); E. Romero, Univ. Nacional de Colombia (Colombia)

866933 Stochastic image registration with user constraints [8669-1 14] I. Kolesov, Georgia Institute of Technology (United States) and Comprehensive Cancer Ctr., Univ. of Alabama at Birmingham (United States); J. Lee, Comprehensive Cancer Ctr., Univ. of Alabama at Birmingham (United States); P. Vela, Georgia Institute of Technology (United States); A. Tannenbaum, Comprehensive Cancer Ctr., Univ. of Alabama at Birmingham (United States)

866934 A novel point-based nonrigid image registration scheme based on learning optimal landmark configurations [8669-115]

T. Wan, Case Western Reserve Univ. (United States); B. N. Bloch, Boston Univ. School of Medicine (United States); S. Danish, Univ. of Medicine and Dentistry of New Jersey (United States); A. Madabhushi, Case Western Reserve Univ. (United States)

866935 Recursive Bayesian estimation of respiratory motion using a modified autoregressive transition model [8669-1 16]

A. A. Abd. Rahni, Univ. Kebangsaan Malaysia (Malaysia) and Univ. of Surrey (United Kingdom); E. Lewis, K. Wells, Univ. of Surrey (United Kingdom) 
866936 Skeleton-based refinement of multi-material volumetric meshes [8669-117] C. Oyarzun Laura, P. Bueno Plaza, K. Drechsler, S. Wesarg, Fraunhofer IGD (Germany)

866937 Image segmentation using normalized cuts with multiple priors [8669-118] E. Ruiz, M. Reisert, Univ. Medical Ctr. Freiburg (Germany)

866938 Sparseness constrained nonnegative matrix factorization for unsupervised 3D segmentation of multichannel images: demonstration on multispectral magnetic resonance image of the brain [8669-119]

I. Kopriva, A. Jukić, Ruđer Bošković Institute (Croatia); X. Chen, Soochow Univ. (China)

866939 Customized hybrid level sets for automatic lung segmentation in chest x-ray images [8669-120]

S. Kamalakannan, Texas Tech Univ. (United States) and National Library of Medicine (United States); S. Antani, R. Long, G. Thoma, National Library of Medicine (United States)

8669 3A An automatic tumor segmentation framework of cervical cancer in T2-weighted and diffusion weighted magnetic resonance images [8669-121]

Y. Kao, W. Li, Institute of Automation (China); H. Xue, C. Ren, Peking Union Medical College Hospital (China); J. Tian, Institute of Automation (China)

$86693 \mathrm{~B}$ False-positive reduction of liver tumor detection using ensemble learning method [8669-122]

A. Miyamoto, J. Miyakoshi, K. Matsuzaki, Hitachi, Ltd. (Japan); T. Irie, Hitachi General Hospital, Hitachi, Ltd. (Japan)

$86693 \mathrm{C} \quad$ Lobar fissure detection using line enhancing filters [8669-123]

T. Klinder, Philips Research Europe (Germany); H. Wendland, Univ. of Lübeck (Germany);

R. Wiemker, Philips Research Europe (Germany)

8669 3D Steerable wavelet transform for atlas based retinal lesion segmentation [8669-124] S. Ali, K. M. Adal, D. Sidibé, Lab. Le2i, CNRS, Univ. de Bourgogne (France); E. Chaum, The Univ. of Tennessee Health Science Ctr. (United States); T. P. Karnowski, Oak Ridge National Lab. (United States); F. Mériaudeau, Lab. Le2i, CNRS, Univ. de Bourgogne (France)

$86693 \mathrm{E}$ Automated segmentation of MS lesions in brain MR images using localized trimmedlikelihood estimation [8669-125]

A. Galimzianova, Ž. Špiclin, B. Likar, F. Pernuš, Univ. of Ljubljana (Slovenia)

8669 3F Development of a novel constellation based landmark detection algorithm [8669-126] A. Ghayoor, The Univ. of lowa (United States) and The Univ. of lowa Hospitals and Clinics (United States); J. G. Vaidya, The Univ. of lowa (United States); H. J. Johnson, The Univ. of lowa (United States) and The Univ. of Iowa Hospitals and Clinics (United States)

$86693 G \quad$ Breast segmentation in MRI: quantitative evaluation of three methods [8669-127] A. Gubern-Mérida, Univ. of Girona (Spain) and Radboud Univ. Nijmegen Medical Ctr. (Netherlands); L. Wang, Fraunhofer MEVIS (Germany); M. Kallenberg, Radboud Univ. Nijmegen Medical Ctr. (Netherlands); R. Martí, Univ. of Girona (Spain); H. K. Hahn, Fraunhofer MEVIS (Germany); N. Karssemeijer, Radboud Univ. Nijmegen Medical Ctr. (Netherlands) 
8669 3H Fuzzy model based object delineation via energy minimization [8669-128]

K. C. Ciesielski, West Virginia Univ. (United States) and Univ. of Pennsylvania (United States); J. K. Udupa, D. Odhner, L. Zhao, Univ. of Pennsylvania (United States)

8669 31 Consistent 4D brain extraction of serial brain MR images [8669-129]

Y. Wang, Northwestern Polytechnical Univ. (China) and Univ. of North Carolina at Chapel Hill (United States); G. Li, J. Nie, P.-T. Yap, Univ. of North Carolina at Chapel Hill (United States); L. Guo, Northwestern Polytechnical Univ. (China); D. Shen, Univ. of North Carolina at Chapel Hill (United States)

8669 3J Statistical representation of high-dimensional enhancement fields with application to consistent enhancement of chest $x$-ray images [8669-130]

Z. Lao, Carestream Health Inc. (United States); X. Zheng, Nanjing Univ. (China); Q. Zou, NJM Insurance Group (United States)

8669 3K Localizing and segmenting Crohn's disease affected regions in abdominal MRI using novel context features [8669-131]

D. Mahapatra, P. J. Schüffler, ETH Zurich (Switzerland); J. A. W. Tielbeek, Academic Medical Ctr. (Netherlands); F. M. Vos, Academic Medical Ctr. (Netherlands) and Delft Univ. of Technology (Netherlands); J. M. Buhmann, ETH Zurich (Switzerland)

8669 3L Glottis segmentation using dynamic programming [8669-132]

J. Chen, B. K. Gunturk, M. Kunduk, Louisiana State Univ. (United States)

$86693 \mathrm{M}$ Effects of T2-weighted MRI based cranial volume measurements on studies of the aging brain [8669-133]

P. Vuong, D. Drucker, C. Schwarz, E. Fletcher, C. DeCarli, O. Carmichael, Alzheimer's Disease Neuroimaging Initiative (United States)

$86693 \mathrm{~N}$ Food image analysis for measuring food intake in free living conditions [8669-134] R. Dibiano, B. K. Gunturk, Louisiana State Univ. (United States); C. K. Martin, Pennington Biomedical Research Ctr. (United States)

866930 DEeP random walks [8669-135]

M. Javanshir Moghaddam, Royal Institute of Technology KTH (Sweden); A. Eslami, N. Navab, Technical Univ. of Munich (Germany)

$86693 \mathrm{P}$ Analysis of brain white matter hyperintensities using pattern recognition techniques [8669-136]

M. Bento, L. Rittner, S. Appenzeller, A. Lapa, R. Lotufo, State Univ. of Campinas (Brazil)

$86693 Q \quad$ An information theoretic approach to automated medical image segmentation [8669-137] E. Corona, Whirlpool Corp. (United States); J. E. Hill, B. Nutter, S. Mitra, Texas Tech Univ. (United States)

8669 3R Automated segmentation of pulmonary lobes in chest CT scans using evolving surfaces [8669-138]

P. Lo, Univ. of California, Los Angeles (United States); E. M. van Rikxoort, Radboud Univ. Nijmegen Medical Ctr. (Netherlands); F. Abtin, S. Ahmad, A. Ordookhani, J. Goldin,

M. S. Brown, Univ. of California, Los Angeles (United States) 
866935 A multiscale graph cut approach to bright-field multiple cell image segmentation using a Bhattacharyya measure [8669-139]

S. M. Kang, J. W. L. Wan, Univ. of Waterloo (Canada)

8669 3Т Automatic segmentation of abdominal wall in ventral hernia CT: a pilot study [8669-140] Z. XU, W. M. Allen, Vanderbilt Univ. (United States); B. K. Poulose, Vanderbilt Univ. Medical Ctr. (United States); B. A. Landman, Vanderbilt Univ. (United States)

$86693 \mathrm{U}$ Graph cuts based left atrium segmentation refinement and right middle pulmonary vein extraction in C-arm CT [8669-141]

D. Yang, Y. Zheng, Siemens Corporate Technology (United States); M. John, Siemens AG (Germany)

$86693 \mathrm{~V}$ Cortical thickness changes related to the processes of maturation and aging in healthy brains [8669-143]

H. H. Cunha, A. C. Santos, S. Rosset, C. E. G. Salmon, Univ. of São Paulo (Brazil)

8669 3W A registration and atlas propagation based framework for automatic whole heart segmentation of CT volumes [8669-144]

X. Zhuang, Shanghai Advanced Research Institute (China); J. Song, S. Zhan, Shu Guang Hospital, Shanghai Univ. of Traditional Chinese Medicine (China); T. Lan, H. Huang, Shanghai Advanced Research Institute (China); M. Hu, S. Ourselin, Univ. College London (United Kingdom); Q. Li, Shanghai Advanced Research Institute (China)

$86693 \mathrm{X}$ Automatic segmentation of the preterm neonatal brain with MRI using supervised classification [8669-145]

S. M. Chiță, M. Benders, P. Moeskops, K. J. Kersbergen, M. A. Viergever, I. Išgum, Univ. Medical Ctr. Utrecht (Netherlands)

8669 3Y Multi-organ segmentation from 3D abdominal CT images using patient-specific weightedprobabilistic atlas [8669-146]

C. Chu, M. Oda, Nagoya Univ. (Japan); T. Kitasaka, Aichi Institute of Technology (Japan);

K. Misawa, Aichi Cancer Ctr. Hospital (Japan); M. Fujiwara, Y. Hayashi, Nagoya Univ.

(Japan); R. Wolz, D. Rueckert, Imperial College London (United Kingdom); K. Mori, Nagoya Univ. (Japan)

POSTER SESSION: SHAPE

866940 Shape manifold regression with spherical harmonics for hippocampus shape analysis [8669-148]

X. Chen, W. Li, Institute of Automation (China); J. Hua, Wayne State Univ. (United States);

X. Zhang, H. He, Institute of Automation (China)

866941 Computation on shape manifold for atlas generation: application to whole heart segmentation of cardiac MRI [8669-149]

X. Zhuang, Shanghai Advanced Research Institute (China); W. Shi, H. Wang, D. Rueckert, Imperial College London (United Kingdom); S. Ourselin, Univ. College London (United Kingdom) 
866942 Interactive 3D segmentation method based on uncertain local region updating in hierarchical MRF graph [8669-151]

S. H. Park, Seoul National Univ. (Korea, Republic of); I. D. Yun, Hankuk Univ. of Foreign

Studies (Korea, Republic of)

866943 Prostate segmentation in 3D TRUS using convex optimization with shape constraint [8669-152]

W. Qiu, J. Yuan, Robarts Research Institute (Canada); E. Ukwatta, Robarts Research Institute (Canada) and The Univ. of Western Ontario (Canada); D. Tessier, Robarts Research Institute (Canada); A. Fenster, Robarts Research Institute (Canada) and The Univ. of Western Ontario (Canada)

866944 A robust model-based approach to detect the mitral annulus in 3D ultrasound [8669-153] B. Graser, D. Wald, German Cancer Research Ctr. (Germany); M. Seitel, Mint Medical GmbH (Germany); M. Grossgasteiger, R. de Simone, Univ. of Heidelberg (Germany); H.-P. Meinzer, German Cancer Research Ctr. (Germany); I. Wolf, German Cancer Research Ctr. (Germany) and Mannheim Univ. of Applied Science (Germany)

866945 Segmentation of the left heart ventricle in ultrasound images using a region based snake [8669-154]

M. Landgren, N. C. Overgaard, A. Heyden, Lund Univ. (Sweden)

866946 Automatic systole-diastole classification of mitral valve complex from RT-3D echocardiography based on multiresolution processing [8669-155]

G. K. W. Tsui, K.-Y. K. Wong, The Univ. of Hong Kong (Hong Kong, China); A. P. W. Lee, The Chinese Univ. of Hong Kong (Hong Kong, China)

866947 Learning based ensemble segmentation of anatomical structures in liver ultrasound image [8669-156]

X. Feng, X. Shen, Q. Wang, Samsung Advanced Institute of Technology (China); J. Kim, Samsung Advanced Institute of Technology (Korea, Republic of); Z. Hao, Samsung Advanced Institute of Technology (China); Y. Hwang, W.-C. Bang, J. D. K. Kim, Samsung Advanced Institute of Technology (Korea, Republic of); J. Kim, Samsung Advanced Institute of Technology (China)

866948 Gland segmentation of breast ultrasound exams [8669-157]

R. Braz, J. Moutinho, M. Freire, A. M. G. Pinheiro, M. Pereira, Univ. da Beira Interior (Portugal)

866949 3D seam selection techniques with application to improved ultrasound mosaicing (Cum Laude Poster Award) [8669-158]

J. F. Kutarnia, P. C. Pedersen, Worcester Polytechnic Institute (United States)

8669 4A Semiautomatic segmentation of atherosclerotic carotid artery lumen using 3D ultrasound imaging [8669-159]

M. M. Hossain, K. AlMuhanna, George Mason Univ. (United States); L. Zhao, School of Medicine, Univ. of Maryland (United States); B. Lal, School of Medicine, Univ. of Maryland (United States) and Veterans Affairs Maryland Health Care System (United States); S. Sikdar, George Mason Univ. (United States)

Author Index 
Proc. of SPIE Vol. $8669866901-20$

Downloaded From: https://www.spiedigitallibrary.org/conference-proceedings-of-spie on 26 Apr 2023 Terms of Use: https://www.spiedigitallibrary.org/terms-of-use 


\title{
Conference Committee
}

\author{
Symposium Chairs
}

Nico Karssemeijer, Radboud University Nijmegen Medical Center (Netherlands)

Ehsan Samei, Duke University (United States)

Conference Chairs

Sebastien Ourselin, University College London (United Kingdom)

David R. Haynor, University of Washington (United States)

\section{Conference Program Committee}

Mostafa Analoui, The Livingston Group, LLC (United States)

Elsa D. Angelini, Telecom ParisTech (France)

Kyongtae Ty Bae, University of Pittsburgh Medical Center (United States)

Christian Barillot, IRISA / INRIA Rennes (France)

Benoit M. Dawant, Vanderbilt University (United States)

Baowei Fei, Emory University (United States)

Aaron Fenster, Robarts Research Institute (Canada)

Bernd Fischer, Universität zu Lübeck (Germany)

Alejandro F. Frangi, Universitat Pompeu Fabra (Spain)

Mona K. Garvin, The University of lowa (United States)

James C. Gee, University of Pennsylvania (United States)

Guido Gerig, The University of Utah (United States)

Tobias Heimann, Siemens AG (Germany)

Bennett A. Landman, Vanderbilt University (United States)

Tianhu Lei, University of Pittsburgh Medical Center (United States)

Boudewijn P. F. Lelieveldt, Leids Universitair Medisch Centrum (Netherlands)

Murray Loew, The George Washington University (United States)

Cristian Lorenz, Philips Medizin Systeme GmbH (Germany)

Frederik Maes, Katholieke Universiteit Leuven (Belgium)

Vincent A. Magnotta, The University of lowa Hospitals and Clinics (United States)

Sunanda D. Mitra, Texas Tech University (United States)

Kensaku Mori, Nagoya University (Japan)

Nassir Navab, Technische Universität München (Germany)

Mads Nielsen, University of Copenhagen (Denmark)

Wiro J. Niessen, Erasmus MC (Netherlands)

Brian S. Nutter, Texas Tech University (United States)

Josien P. Pluim, University Medical Center Utrecht (Netherlands) 
Jerry L. Prince, Johns Hopkins University (United States)

Sonia Pujol, Brigham and Women's Hospital (United States) and Harvard Medical School (United States)

Daniel Rueckert, Imperial College London (United Kingdom)

Punam K. Saha, The University of lowa (United States)

Olivier Salvado, Commonwealth Scientific and Industrial Research Organisation (Australia)

Julia A. Schnabel, University of Oxford (United Kingdom)

Colin Studholme, University of Washington (United States)

Martin A. Styner, The University of North Carolina at Chapel Hill (United States)

Philippe Thévenaz, Ecole Polytechnique Fédérale de Lausanne (Switzerland)

Jayaram K. Udupa, The University of Pennsylvania Health System (United States)

Tomaž Vrtovec, University of Ljubljana (Slovenia)

Andreas Wahle, The University of lowa (United States)

Session Chairs

1 Segmentation

Punam K. Saha, The University of lowa (United States)

2 DTI/Functional

Sonia Pujol, Brigham and Women's Hospital (United States) and Harvard Medical School (United States)

3 Shape Appearance

Jerry L. Prince, Johns Hopkins University (United States)

4 Temporal and Motional Analysis

Martin A. Styner, The University of North Carolina at Chapel Hill (United States)

5 OCT and Ultrasound

Aaron Fenster, Robarts Research Institute (Canada)

$6 \quad$ Lung

Josien P. Pluim, University Medical Center Utrecht (Netherlands)

7 Registration

Benoit M. Dawant, Vanderbilt University (United States)

8 Segmentation and Localization

Tomaž Vrtovec, University of Ljubljana (Slovenia) 
9 Keynote and 2D-3D Registration

David R. Haynor, University of Washington (United States)

10 Statistics of Images and Structures

Murray H. Loew, The George Washington University (United States)

11 Label Fusion

Baowei Fei, Emory University (United States)

Poster Sessions

Bennett A. Landman, Vanderbilt University (United States)

Wiro J. Niessen, Erasmus MC (Netherlands) 
Proc. of SPIE Vol. $8669866901-24$

Downloaded From: https://www.spiedigitallibrary.org/conference-proceedings-of-spie on 26 Apr 2023 Terms of Use: https://www.spiedigitallibrary.org/terms-of-use 